\title{
Relação entre obesidade e ocorrência de síndrome metabólica equina em cavalos Crioulos
}

Camila Cantarelli[a]", Stefano Leite Dau ${ }^{[a]}$, Simone Stefanello $0^{[a]}$, Marcos da Silva Azevedo ${ }^{[b]}$, Grasiela de Bastianiic], Heloisa Einloft Palmaa ${ }^{[a]}$ Karin Érica Brass ${ }^{[a]}$, Flávio De La Côrte ${ }^{[a]}$

\footnotetext{
[a] Universidade Federal de Santa Maria (UFSM), Santa Maria, RS, Brasil

[b] Universidade Federal de Santa Catarina (UFSC), Curitibanos, SC, Brasil

[c] IMED, Passo Fundo, RS, Brasil
}

*Autor correspondente

e-mail: camilacantarelli@yahoo.com.br

\section{Resumo}

Os cavalos da raça Crioula, que antes eram mantidos soltos em campos nativos, passaram a ser criados em cocheiras ou pastagens com alimentação rica em energia. Essas mudanças no manejo e tipo de alimentação resultaram no surgimento de problemas como as doenças ortopédicas do desenvolvimento e a obesidade. Atualmente, sabe-se que animais obesos estão mais predispostos a desenvolver a síndrome metabólica equina (SME), que se caracteriza pelo aumento da adiposidade corporal, resistência insulínica (RI) e laminite. 0 objetivo deste trabalho foi investigar a SME em cavalos Crioulos considerados obesos e avaliar a aplicabilidade do teste dinâmico com glicose de milho via oral (TGO) para o seu diagnóstico. Foram selecionados 22 cavalos de diferentes propriedades do Rio Grande do Sul, com registro na Associação Brasileira de Criadores de Cavalos Crioulos (ABCCC). Após obtenção do histórico clínico e de manejo, bem como exame físico completo, foi realizado exame radiográfico dos cascos e mensuração ultrassonográfica da espessura do tecido adiposo subcutâneo na região da base da cola, cernelha, atrás da escápula e retroperitoneal. Medidas morfométricas da circunferência do pescoço (CP), altura da crista do pescoço (HCP), circunferência torácica (CT), altura na região da cernelha e peso foram mensuradas; além do escore de condição corporal (ECC), o escore da crista do pescoço (ECP) também foi determinado. Os animais foram alocados em três grupos de acordo com seu ECC e presença ou ausência de laminite: G1 (6/22): ECC<7, tido como controle; G2 (8/22): ECC $\geq 7$ sem laminite; G3 (8/22): ECC $\geq 7$ com laminite. A avaliação da curva glicêmica foi realizada por meio do TGO após um jejum de oito horas, sendo coletadas amostras de sangue antes e aos 30, 60, 75, 90, 120, 150, 180, 210 e 240 minutos da administração de glicose. A concentração plasmática de insulina foi mensurada antes do TGO, aos 75 min, após os 90min nos animais 
que apresentaram pico de glicose, e também mais tardiamente (120, 150 ou 180min pós TG0). Também foi realizada a mensuração de triglicerídeos na amostra basal. Os animais obesos com laminite (G3) apresentaram as maiores medidas morfométricas e concentrações plasmáticas $(\mu \mathrm{UI} / \mathrm{mL})$ de insulina basal $(\mathrm{G} 1=2,2 \pm 0,2 ; \mathrm{G} 2=3,9 \pm 0,2 ; \mathrm{G} 3=9,5 \pm 0,9)$ e aos 75min (G1 = $6 \pm 1 ; \mathrm{G} 2=9,5 \pm 2 ; \mathrm{G} 3=18,5 \pm 7)$ dentre os grupos. Diferenças $(\mathrm{P}<0,05)$ morfométricas (peso, HCP, ECP) e metabólicas (triglicerídeos, tempo para concentração máxima de glicose, área sob a curva de concentração de glicose ao longo do tempo, tempo de retorno a níveis basais de glicose) foram observadas entre animais do G1 comparados com os do G2 e G3. Em nove de 16 animais obesos (56,25\%), o pico de glicose, bem como o pico de insulina em resposta ao TGO, ocorreu em um tempo superior (120 - 180min) ao descrito na literatura (60 - 90min). Além disso, o tempo necessário para a glicose retornar a níveis basais foi diferente entre os grupos, caracterizando resistência à insulina em 69\% $(n=11 / 16)$ dos animais obesos. A detecção da resistência à insulina por meio do TGO somente foi possível porque a curva da resposta glicêmica ao teste foi determinada, uma vez que as concentrações plasmáticas de insulina se mantiveram dentro dos valores de referência. A gordura subcutânea da região da base da cola foi o fator mais fortemente correlacionado $(R=0,87)$ com a resistência à insulina. A amostragem aos 75 min, preconizada para detecção de hiperinsulinemia, foi considerada inadequada se realizada sem a curva glicêmica em animais obesos. Estes resultados revelam diferenças claras relacionadas com a obesidade nas respostas de glicose e insulina de cavalos Crioulos frente ao TGO, reforçando a associação dessa condição com distúrbios metabólicos. Além disso, aumentam a acurácia no diagnóstico da SME, permitindo sua identificação antes da ocorrência de laminite.

Palavras-chave: Teste de glicose oral. Insulina. Morfometria. 